\title{
Transaortic resection of an apical left ventricular fibroelastoma facilitated by a thoracoscope
}

\author{
Jon-Cecil Walkes, MD, Charudatta Bavare, MD, Shanda Blackmon, MD, MPH, and Michael J. Reardon, MD, Houston, Tex
}

$\mathrm{T}$ he left ventricular apex is a difficult area to access surgically without a left ventricular cardiotomy and its attendant ventricular myocardial compromise. This is of particular concern in patients with left ventricular tumors for two reasons. The first reason is that most of these patients are young without any other cardiovascular disease and have a good prognosis if the tumor is benign. The second reason is that the prognosis of these patients depends on a complete surgical resection with good margins, and cardiotomy carries with it some risk of cutting into the tumor because of hampered visualization. Traditional transaortic resection of left ventricular tumors avoids a cardiotomy but affords poor visualization and can lead to a compromise of tumor margins, which affects long-term outcome. In this case report we describe a novel technique of intraoperative visualization and resection of a benign tumor in the left ventricular apex using a transaortic approach and the assistance of a standard thoracoscope and instruments available to most thoracic surgeons.

\section{Clinical Summary}

A 61-year-old man was admitted to the hospital with recurrent transient ischemic attacks over the preceding 1 week. The patient did not have any antecedent neurologic condition and had no history of atrial fibrillation. A computed tomographic scan of the brain did not reveal any infracts or intracranial bleeding. Carotid duplex did not show any significant stenosis or ulcerated plaques. A transthoracic echocardiogram showed an apical left ventricular mass and good left ventricular function (Figure 1, A, B). The patient was referred for surgery. Preoperative coronary catheterization did not reveal any significant stenoses.

A median sternotomy was performed. Cardiopulmonary bypass was initiated with distal ascending aortic cannulation and bicaval venous cannulation. Antegrade cardioplegia and retrograde cardioplegia through a catheter in the coronary sinus were given. A sump catheter was placed in the left atrium through a purse string suture in the right superior pulmonary vein. The aorta was circumferentially transected $1 \mathrm{~cm}$ distal to the sinotubular junction. The aortic valve was gently retracted, and a 2-mm thoracoscope was passed into the left ventricular cavity (Figure $1, C$ ) to visualize the left ventricular mass (Figure 2, A). This afforded clear visualization and enabled complete resection of the mass (Figure 2, B). Frozen-

From The Methodist Hospital, Houston, Tex

Received for publication May 1, 2007; accepted for publication May 11, 2007.

Address for reprints: Michael J. Reardon, MD, 6560 Fannin St, 1006, Houston, TX 77030 (E-mail: mreardon@tmh.tmc.edu).

J Thorac Cardiovasc Surg 2007;134:793-4

$0022-5223 / \$ 32.00$

Copyright (C) 2007 by The American Association for Thoracic Surgery

doi:10.1016/j.jtcvs.2007.05.019 section examination of the mass was consistent with a fibroelastoma. Formal histologic examination of the mass revealed a mass consisting predominantly of papillary frond structures lined by endothelial cells with a myxoid stroma and a hyalinized core. This was consistent with a diagnosis of papillary fibroelastoma.

The postoperative course was uneventful. The patient remains asymptomatic at the 8-month follow-up with no evidence of tumor recurrence.

\section{Discussion}

Papillary fibroelastoma is the third most common type of benign heart neoplasm. ${ }^{1}$ Although commonly found on valve surfaces, this benign neoplasm can occur anywhere in the endocardium. Most fibroelastomas are found in the left side of the heart $(>95 \%)$, and clinical presentation is dominated by systemic embolization, particularly cerebral embolization. ${ }^{1}$ Despite the diminutive size of the tumors themselves, surgical excision is necessary to prevent this devastating complication.

Tumors of the left ventricular cavity can be approached in 3 ways: transaortic transvalvular, transmural, or transmitral transvalvular approach. The apical location of this tumor would make a transmitral approach extremely challenging. A transmural approach would require an incision made in the viable left ventricular muscle with all its attendant muscle dysfunction. A transaortic transvalvular approach leads to the least dysfunction. However, when performed in the traditional way, this approach leads to limited visualization. The technique described here leads to excellent visualization of the tumor, which helps the excision of tumor and confirmation of complete excision and good gross margins. The only additional instrumentation needed is a thoracoscope, which is readily available in most thoracic centers today. This approach has been used for the excision of left ventricular thrombi ${ }^{4,5}$ but has not been used for tumor resection.

This case also highlights an unusual cause of transient ischemic attacks and the high index of suspicion required to secure the diagnosis. Resection of fibroelastomas is safe and curative.

\section{References}

1. McAllister HA, Fenoglio JJ. Tumors of the Cardiovascular System. Atlas of Tumor Pathology, 2nd ser., fasc. 15. Washington: Armed Forces Institute of Pathology; 1978:141.

2. Brown RD Jr, Khandheria BK, Edwards WD. Cardiac papillary fibroelastoma: a treatable cause of transient ischemic attack and ischemic stroke detected by transesophageal echocardiography. Mayo Clin Proc. 1995;70:863-8

3. McFadden PM, Lacy JR. Intracardiac papillary fibroelastoma: an occult cause of embolic neurologic deficit. Ann Thorac Surg. 1987;43:667-9.

4. Mazza IL, Jacobs JP, Aldousany A, Chang AC, Burke RP. Videoassisted cardioscopy for left ventricular thrombectomy in a child. Ann Thorac Surg. 1998;66:248-50.

5. Tsukube T, Okada M, Ootaki Y, Tsuji Y, Yamashita C. Transaortic video-assisted removal of a left ventricular thrombus. Ann Thorac Surg. 1999;68:1063-5. 


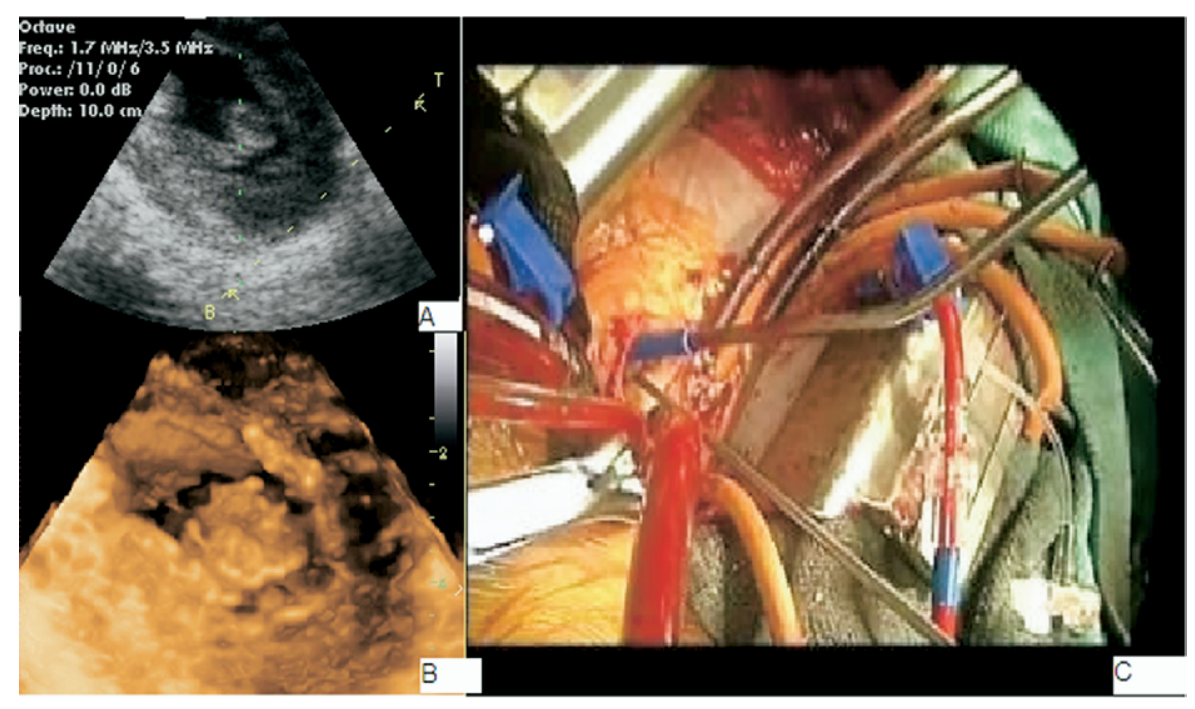

Figure 1. A, Two-dimensional echocardiogram showing left ventricular mass. B, Three-dimensional echocardiogram showing left ventricular mass. C, Transaortic insertion of thoracoscope.

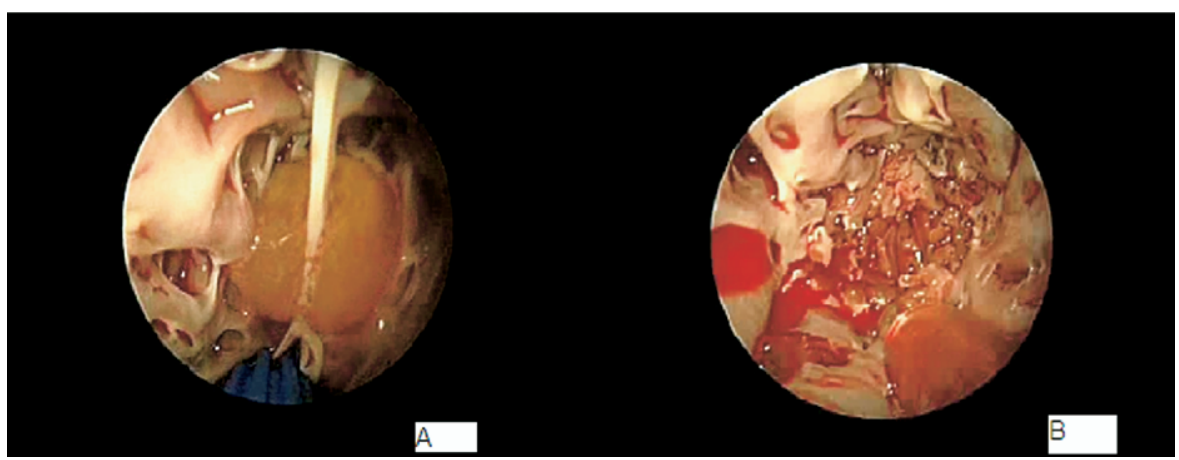

Figure 2. A, Thoracoscopic view of the left ventricular mass. $B$, Thoracoscopic view after excision of left ventricular mass. 